\title{
Ecologia política: onde está a política?*
}

\section{Political Ecology: Where is the Politics?**}

\author{
Peter A. WALKER ${ }^{* * *}$
}

\begin{abstract}
RESUMO
Quanta diferença prática a ecologia política realmente faz? Quais poderiam ser os obstáculos para uma ecologia política mais construtivamente comprometida - para uma ecologia política mais plenamente política? Estas são questões que este artigo levanta de forma breve, mas não tem a pretensão de responder de nenhuma maneira substancial. Antes, espera-se e acredita-se que estas questões serão minuciosamente discutidas em encontros futuros.
\end{abstract}

Palavras-chave: ecologia política; política; ecologia política popular.

\begin{abstract}
How much practical difference does political ecology actually make? What might be the obstacles to a more constructively engaged political ecology - to a more fully political political ecology? These are the questions that this essay raises briefly, but does not pretend to answer in any substantial way. Rather, it is hoped and believed that these questions will be discussed at length in future venues.
\end{abstract}

Keywords: political ecology; politics; popular political ecology.

\section{Introdução}

Eu acredito que a ecologia política poderia contribuir de forma importante, pelo menos para questionar publicamente esta pilhagem [da América Latina], e que nós poderíamos ter insights úteis para os ativistas - e nós não fazemos tanto quanto poderíamos a este respeito. (Anthony Bebbington) ${ }^{1}$
Para os ecologistas políticos da atualidade, pode parecer estranho - ridículo talvez - perguntar se a ecologia política é suficientemente política. Já se passaram quase duas décadas desde que Michael Watts queixou-se de que as expressões dominantes da ecologia política dos anos 1980 mostravam "uma notável falta de conteúdo político... Não há quase uma sensação de disputa, luta e conflito e como o jogo duro ${ }^{2}$ da vida diária" molda as relações humanas com o meio ambiente (WATTS, 1990, p. 128-129). Desde então, houve uma explosão de estudos (demasiado numerosos para

\footnotetext{
"Artigo originalmente publicado em Progress in Human Geography, v. 31, n. 3, p. 363-369, 2007. Tradução: Vicente Rosa Alves; Revisão: Júlia Spatuzzi Felmanas. "* Na literatura sobre "policy analysis" o conceito de "politics" é empregado para denominar os processos políticos. Para Frey (2000, p. 216) "no quadro da dimensão processual 'politics' tem-se em vista o processo político, frequentemente de caráter conflituoso, no que diz respeito à imposição de objetivos, aos conteúdos e às decisões de distribuição". Ver FREY, Klaus. Políticas públicas: um debate conceitual e reflexões referentes à prática da análise de políticas públicas no Brasil. In: Planejamento e políticas públicas, n. 21, jun. 2000 (N.T.).

**** Professor do Departamento de Geografia da Universidade de Oregon, Eugene. Email: pwalker@uoregon.edu

${ }^{1}$ Comunicação pessoal, 20 de agosto de 2006.
} 
citar) na ecologia política que aceitaram o desafio de tratar de um modo mais sofisticado o papel da política dentro das relações entre o homem e o meio ambiente. Ao comparar a ecologia política com outras tradições intelectuais que tentam explicar os problemas ambientais (tais como a ecoescassez e a modernização ecológica), Robbins (2004) constata que a característica que define o campo hoje em dia é "a diferença entre uma ecologia política e uma apolítica" (grifos no original). A política tornou-se tão central para a área que sérias críticas têm sido feitas ao fato de que a ecologia política se tornou "política sem ecologia" (VAYDA; WALTERS, 1999).

No entanto, é possível indagar se, através de suas próprias definições da palavra "política", a ecologia política tem correspondido plenamente às expectativas de sua promessa de levar a política a sério. Em seu artigo "Locating the political in political ecology", Paulson et al. (2003, p. 209, grifo nosso), definem política como "as práticas e processos através dos quais o poder, em suas múltiplas formas, é exercido e negociado". Os autores comentam que um dos desafios-chave da ecologia política é "desenvolver maneiras para aplicar os métodos e conclusões (da pesquisa em ecologia política) na abordagem das preocupações socioambientais" (p. 208). Na verdade, esta preocupação para tornar a política não apenas objeto de pesquisa, mas uma prática, tem há muito tempo sido um objetivo explícito e central da ecologia política. Peet e Watts (1996, p. xi), por exemplo, declaram que a ecologia política "é guiada por um compromisso normativo e político com o potencial libertário das preocupações ambientais". ${ }^{4}$ Da mesma maneira, Robbins (2004, p. 13) comenta que a ecologia política é explicitamente e sem nenhum constrangimento normativa, procurando "plantar as sementes para recuperar e afirmar maneiras alternativas de fazer o manejo dos recursos [...] o objetivo [...] é preservar e desenvolver maneiras específicas, exequíveis e apropriadas de ganhar a vida". O compromisso verbal da ecologia política de não apenas estudar, mas de exercer poder político - para fazer a diferença, para "plantar uma semente" - tanto para os humanos como para a natureza parece não estar em questão.

Mas quanta diferença prática a ecologia política realmente faz? Quais poderiam ser os obstáculos para uma ecologia política mais construtivamente comprometida - para uma ecologia política mais plenamente política? Estas são questões que este artigo levanta de forma breve, mas não tem a pretensão de responder de nenhuma maneira substancial. Antes, espera-se e acredita-se que estas questões serão minuciosamente discutidas em encontros futuros. Parece um consenso geral de que o "potencial libertário" deste campo é, em grande medida, a sua raison d'etre - mesmo que ele não seja plenamente realizado na prática. Neste caso, mesmo a possibilidade de que a ecologia política, com todas as suas enormes passadas intelectuais, possa ser em grande parte inativa e, no fim das contas, apolítica e impotente, na prática essas questões merecem ser levadas a sério. São necessárias diretrizes claras para o que constitui as práticas e o poder de uma ecologia política ética. As seções seguintes consideram alguns dos desafios, realizações e possibilidades.

\section{As realizações}

Tem-se observado que a ecologia política tem demonstrado coletivamente um surpreendente tipo de ambivalência com respeito à política ambiental, interpretado como programas e instituições formais da gestão ambiental (WALKER, 2006). Este artigo considera o compromisso da ecologia política com a política num sentido amplo: política como a panóplia de "processos e mecanismos" por meio dos quais o poder é expandido e negociado. Com raízes nos estudos sobre camponeses e desenvolvimento, teoria dos movimentos sociais e estudos sobre o conhecimento indígena e as lutas simbólicas e discursivas sobre os recursos (WATTS, 2000), poder-se-ia esperar que a ecologia política se sentisse muito à vontade e envolvida nestes reinos relativamente informais da política e do poder não institucionais. Na verdade, muitos ecologistas políticos podem e se envolvem neste tipo de política - uma "ecologia política popular" 5 que associa a pesquisa diretamente aos esforços dos ativistas para melhorar o bem-estar humano e a sustentabilidade ambiental por intermédio de várias formas de ativismo e de organizações populares locais.

\footnotetext{
${ }^{2}$ The rough and tumble.

3 "politics without ecology".

${ }^{4}$ The liberatory potential of environmental concerns.

${ }^{5}$ A "popular political ecology".
} 
Piers Blaikie comentou que a ecologia política tornou-se tão ampla e expandida ${ }^{6}$ que a citação muitas vezes acontece aleatoriamente e uma seleção de alguns exemplos da ecologia política em ação não faz necessariamente justiça ao grande número de pesquisadores não mencionados fazendo um trabalho similar excelente. Apesar de tudo, alguns exemplos de tais trabalhos incluem o trabalho de Tony Bebbington com os movimentos de povos indígenas, políticas democráticas e organizações não governamentais na América Latina (ver BEBBINGTON, 2007); os esforços de Simon Batterbury para transformar a retórica do "empoderamento" local" em mudanças in loco na África Ocidental e em outros lugares (ver BEBBINGTON et al., 2007); os trabalhos das geógrafas feministas, tais como o extenso trabalho de Diane Rocheleau sobre a gestão dos recursos de gênero e o papel da ciência "participativa" versus a ciência "formal" no Quênia e em outros lugares (ver ROCHELEAU, 2007); a colaboração pioneira de Nathan Sayre com as organizações de base para construir alianças ecologicamente informadas e socialmente sustentáveis entre fazendeiros de gado e ambientalistas, procurando trazer paz para as chamadas "guerras territoriais" na América Ocidental (SAYRE, 2005); o trabalho de Tim Forsyth (e outros), que promove a "ciência híbrida" combinando a história oral e outras formas de conhecimento local com a ciência formal para empoderar a população habitualmente excluída do processo científico formal, muitas vezes por meio da reformulação das questões e do desafio às ortodoxias existentes (ver FORSYTH, 2003; FORSYTH; WALKER, 2007). Muitos outros ecologistas políticos hoje em dia estão se envolvendo em múltiplas formas de "ecologia política popular"; eles se envolvem, inclusive, com experiências que estão mais próximas, de um modo que fazem contribuições práticas importantes, mas são quase invisíveis dentro das instituições acadêmicas. Os exemplos poderiam continuar. Basta dizer que eles ilustram de forma clara que muitos ecologistas políticos podem e colocam suas ideias em ação; eles colocam de forma deliberada as ideias da ecologia política em prática para exercer o poder de efetuar mudanças reais para sempre uma ecologia política que é política no mais completo e mais positivo sentido.

\section{Os silêncios}

Apesar destas realizações, há, contudo, uma ampla preocupação entre os ecologistas políticos de que o campo como um todo permaneça em grande medida voltado para dentro, confinado às publicações acadêmicas que são indisponíveis ou ininteligíveis àqueles que poderiam se beneficiar da pesquisa e restrito às conferências e seminários frequentados quase que exclusivamente por elites acadêmicas privilegiadas e que pensam de forma parecida, que não experimentam diretamente elas próprias a fome, a doença, a pobreza, os riscos e a degradação ambiental sobre os quais elas estudam, escrevem e falam. Alguns ecologistas políticos começaram a questionar a ética institucional implícita da "torre de marfim": não importa o quanto brilhe, uma luz numa caixa fechada de forma hermética não ilumina. E consome recursos, energia e espaço no processo. Além disso, a pesquisa na ecologia política não é neutra ou gratuita para as pessoas que fornecem as histórias e as informações que são a matéria-prima das carreiras acadêmicas relativamente ricas e confortáveis. Por exemplo, para muitos sujeitos de pesquisa, especialmente nas sociedades menos desenvolvidas, o tempo gasto em entrevistas, discussões de grupo ${ }^{8}$ e assim por diante resulta num custo significativo para as atividades produtivas vitais, muitas vezes com poucos benefícios tangíveis em troca. Como reclamou um eminente ecologista político, "pesquisadores irresponsáveis ${ }^{9}$ tiram o máximo e dão o mínimo em troca - eu vi colegas dedicarem-se ao trabalho de campo por três semanas, publicarem três ou quatro papers como único autor e nunca mais voltarem".

Em outras palavras, a ampla virada moral na geografia contemporânea (SAYER; STORPER, 1997; SMITH, 2000) ainda não penetrou e desenvolveu-se plenamente numa análise ética dos métodos e práticas da ecologia política. Junto com as expressões mais gerais da accountability em pesquisas desenvolvidas em lugares e ambientes próximos e distantes (DRIVER, 1991; CORBRIDGE, 1993; CLOKE, 2002), a ecologia política adotou uma posição "que privilegia os direitos e preocupações (muitas vezes a base da subsistência) dos pobres sobre aqueles das elites econômica e politicamente poderosas" (BRYANT; JAROSZ, 2004, p. 808).

\footnotetext{
${ }^{6}$ Sprawling.

${ }^{7}$ Local empowerment.

${ }^{8}$ Focus groups.

${ }^{9}$ Fly-by-night researchers.
} 
No entanto, curiosamente, esta preocupação para proteger os grupos subordinados de serem explorados pelas elites políticas e econômicas não se estendeu a uma autocrítica plenamente desenvolvida por parte dos próprios ecologistas políticos como elites acadêmicas (que são também elites sociais e econômicas) - embora com exceções louváveis, especialmente entre ecologistas feministas (por ex., ROCHELEAU et al., 1996; JAROSZ, 2004). Num campo que é fundamentalmente normativo e que coloca a ética social no centro de sua agenda, a ética da própria pesquisa na ecologia política como processos e práticas de poder permanece surpreendentemente subexaminada. Curiosamente, nenhum campo fez mais para demonstrar que ciência e pesquisa são manifestações de poder e política (LEACH; MEARNS, 1996; STOTT; SULLIVAN, 2000; FORSYTH, 2003), não obstante a ecologia política em conjunto tenha feito relativamente pouco para examinar a sua própria casa.

Deveria ser dito que uma grande parte das práticas éticas das "ações de responsabilidade social"10 por parte dos ecologistas políticos são invisíveis e difíceis de mensurar. Muitos pesquisadores podem e fazem esforços para assegurar benefícios tangíveis para nações, comunidades e indivíduos cujas histórias, tempo e conhecimento sustentam os ecologistas políticos com suas carreiras. No entanto, nas instituições e produtos formais da ecologia política como uma profissão (conferências, grupos de especialistas ${ }^{11}$, publicações e assim por diante), este ato das "ações de responsabilidade social" - o ato de uma política de pesquisa ética e autoconsciente - não é muitas vezes particularmente visível.

Como uma medida muito rudimentar, considere as apresentações de pesquisa na Conferência Anual da Associação de Geógrafos Americanos em Chicago no ano de 2006. Dos 79 papers e resumos identificados pela palavra-chave "ecologia política", praticamente todos manifestavam uma preocupação com a ética ou com a justiça para com seus sujeitos de pesquisa (embora alguns possam ser considerados "teoria pura"). Contudo, apenas sete (9\%) identificaram esforços práticos para aumentar a subsistência, empoderar politicamente, dar mais "voz", assegurar a sobrevivência cultural ou reduzir os riscos para as pessoas que são os sujeitos da pesquisa como uma parte central do projeto de pesquisa. Pode ser inferido que a intenção de $91 \%$ das pesquisas restantes em ecologia política nesta amostra era aumentar o conhecimento de forma a assegurar, em algum momento no futuro e de uma maneira não especificada, benefícios tangíveis para os sujeitos de pesquisa. Alternativamente, e de uma maneira mais cínica, pode ser inferido que, como uma formação institucional, a ecologia política não dá alta prioridade às práticas relacionadas em devolver alguma coisa às comunidades - talvez, até mesmo, que uma grande parte da ecologia política não tem diretrizes formuladas para efetuar uma mudança positiva; que é em grande medida exploradora, assim como ineficaz, impotente, apolítica.

Como descrito no início deste artigo, tal inferência não reflete claramente a ecologia política como um todo. Ela sugere, contudo, a necessidade de uma autoconsciência crítica e vigilante. Parafraseando o fantasma das coisas do futuro de Dickens ${ }^{12}$, essas são sombras das coisas que poderão acontecer - não as sombras das coisas que acontecerão. No entanto, se estas preocupações têm afinal alguma validade, como podemos explicar as incertezas das práticas éticas da ecologia política quando uma ética política libertária e normativa está no próprio centro do campo de estudos?

\section{Desafios institucionais}

Este artigo não pretende dar respostas, mas oferece algumas ideias que podem ajudar a estimular uma discussão mais completa. Para começar, os ecologistas políticos sondados para este artigo sugeriram que existem coações institucionais significativas dentro da academia que limitam a capacidade dos pesquisadores de se envolver num trabalho mais aplicado ou ativista. ${ }^{13}$ Por exemplo, um

\footnotetext{
10 "Giving back".

${ }^{11}$ Specialty groups.

${ }^{12}$ Dickens' ghost of things yet to come. A paráfrase que o autor faz aqui se refere a um trecho de um pequeno conto de Charles Dickens intitulado Um conto de natal (lançado pela editora L\&PM em 2009). Há outra edição publicada pela Publicações Europa-América que leva outro título: O natal do Sr. Scrooge - a história de um natal assombrado (N.T.).

${ }^{13}$ Em 8 de agosto de 2006, este autor apresentou uma questão ao list serve sobre Ecologia Política e Cultural da Associação de Geógrafos Americanos perguntando em que medida os ecologistas políticos "devolviam" aos seus sujeitos de pesquisa. A questão obteve 19 respostas (isto é "fora da lista") de 14 geógrafos. Nenhuma reclamação pode ser feita de que esta foi uma amostra representativa cientificamente válida, mas ela reflete as visões de alguns indivíduos bem reconhecidos na área. Deveria ser digno de nota que muitas das coações institucionais registradas eram específicas às instituições acadêmicas dos Estados Unidos. Uma discussão similar sobre o mesmo list serve foi iniciada por William Moseley em 8 de agosto de 2006, na qual vários ecologistas políticos mencionaram que existem melhores oportunidades institucionais para a pesquisa aplicada no Reino Unido.
} 
proeminente ecologista político descreve o trabalho com as organizações não governamentais humanitárias nacionais e estrangeiras e publica um livro previsto para um amplo público de leitores. Este pesquisador também constatou, contudo, que: "O contato que tenho com um público mais amplo está relacionado, eu acredito, com o fato de eu ser um professor universitário em tempo integral e não estar mais sendo avaliado por um comitê do campus sobre a natureza de minha contribuição intelectual. Isto é, eu acho que a nossa posição na academia restringe o nosso trabalho 'aplicado' (o trabalho de elaboração de políticas) o qual não é visto com bons olhos pelos comitês". Outro eminente ecologista político comentou sobre o "caráter frenético da acelerada vida acadêmica": "Nos últimos anos, o ritmo de trabalho nas instituições acadêmicas assemelha-se muito ao de uma redação de jornal. Eu trabalho sob um prazo-limite constante. Todos os dias trata-se de despachar as coisas da minha mesa e lidar com outros assuntos; a máquina está girando e eu tenho pouco tempo para pensar" - muito menos para mudar o mundo. No entanto, outro proeminente ecologista político observou que, em discussões sobre a promoção acadêmica, "publicações em língua estrangeira são consideradas serviço e não pesquisa - o que é isso se não um obstáculo ao nosso envolvimento e, particularmente, ao envolvimento em debates públicos e políticos nas nações onde trabalhamos". Além disso, um currículo de graduação raramente exige ou mesmo dá alguma instrução sobre a ética ou as habilidades em relação às ações que dão algo de volta às comunidades.

Esta preocupação com as barreiras institucionais para pesquisadores engajados tornou-se um tema importante na ecologia política e está refletida no futuro livro de Simon Batterbury e colegas (BATTERBURY; HOROWITZ, 2007) e numa importante conferência. Estes autores sugerem que o envolvimento da ecologia política com diferentes públicos "fora da academia" exigirá a aceitação de possíveis riscos profissionais, assim como uma responsabilização pelo modo como o trabalho da ecologia política será traduzido em ações. Os autores também observam o desafio de trabalhar de forma construtiva com os formuladores de política que são muitas vezes o objeto da crítica na ecologia política, assim como a frustração de públicos que normalmente são favoráveis à ecologia política, porque essa normalmente só oferece uma crítica - e mesmo assim numa linguagem que é frequentemente ininteligível mesmo para profissionais com um alto nível de escolaridade. Os autores também manifestam uma preocupação de que a pureza intelectual e a linguagem inacessível possam constituir uma fuga da responsabilidade pelas implicações da pesquisa, uma vez que é improvável que seus trabalhos sejam lidos e entendidos, muito menos que tenham ou exerçam alguma influência.

Estas coações, evidentemente, não são de modo algum únicas para a ecologia política - elas são problemas para a geografia e os pesquisadores da academia em geral. Contudo, por causa de sua temática e de sua forte postura normativa, denota-se que a ecologia política goza de uma posição especial e de um tipo especial de obrigação ética.

\section{Conclusão: o desafio especial da ecologia política como prática ética}

Apesar de alguns esforços louváveis (por ex., JAROSZ, 2004) não existe até agora, de forma clara, nenhuma ética escrita dos métodos e práticas da ecologia política. Como observou Paul Robbins, os ecologistas políticos são "forçados a se perguntar quem ganha e quem perde com a pesquisa e a refletir muito sobre como alguém deveria agir no panorama da ecologia política" (ROBBINS, 2004, p. 201). Como sabemos quais "sementes" nós estamos - ou deveríamos - estar plantando? No entanto, na ecologia política estas questões tendem a ser abordadas de uma maneira um tanto ad hoc pelos pesquisadores. O campo como um todo fornece poucas diretrizes. Como observou o ecologista político Eric Perramond, a tendência rumo a práticas éticas mais autorreflexivas por parte dos ecologistas políticos começou, mas permanece debilmente desenvolvida:

Envolver colegas a nível internacional e agentes com conhecimento local tornar-se-á o modo de operação para quase todos os ecologistas políticos que realizam trabalho de campo na geografia como se tornou na maior parte dos projetos da antropologia e arqueologia. Já que esta parece ser a direção tomada, a ecologia política estará mais bem servida e será mais útil se houver diretrizes éticas claras para conduzir e concluir tais iniciativas... Os métodos e as operações de campo da ecologia política serão dramaticamente diferentes das práticas do passado (Eric Perramond $\left.{ }^{14}\right)$.

\footnotetext{
${ }^{14}$ Comunicação pessoal, 17 de julho de 2006, citado com permissão.
} 
Esta falta de diretrizes éticas claras para a pesquisa é quase única entre as comunidades acadêmicas. Apesar disso, a ecologia política parece ter uma obrigação especial para estabelecer tais diretrizes por, pelo menos, três razões. Primeiro, o assunto da ecologia política é tipicamente pobreza, fome, injustiça social ou ambiental e degradação dos recursos. Com respeito à fome, o filósofo Peter Singer (1972) argumentou que se os privilegiados do mundo pudessem melhorar de maneira significativa o bem-estar daqueles em situação de miséria sem causar dano excessivo a si próprios, isso não seria uma escolha, mas uma obrigação ética. O filósofo Arne Naess (1973) e muitos outros fizeram argumentações semelhantes relativamente às obrigações éticas com respeito à natureza. Embora alguns ecologistas políticos contestem algumas interpretações destas posições filosóficas (GUHA, 1989), praticamente todos eles compartilham a preocupação filosófica central para uma justiça social e ambiental - para uma "ecologia da libertação"15 (PEET; WATTS, 1996). Como a área amadureceu e prosperou, os ecologistas políticos estão excepcionalmente bem posicionados para contribuir para esta libertação, para "devolver" a seus sujeitos de pesquisa - embora potencialmente a um custo não desprezível para suas próprias carreiras. Em segundo lugar, uma ecologia política não engajada não é moralmente neutra: os ecologistas políticos "tiram" de seus sujeitos de pesquisa. A grande maioria das pesquisas na ecologia política consiste de estudos sobre os pobres e desfavorecidos, frequentemente do terceiro mundo. Os ecologistas políticos constroem as suas carreiras a partir dos pobres e desfavorecidos do mundo - ou como informação coletada por meio de pesquisa e transformada em "mercadorias" profissionais (publicações de periódicos etc.) - ou por meio de subsídios de receitas públicas que são (cada vez mais) taxados dos pobres no primeiro mundo; ou por meio de financiamento de um limitado fundo comum da filantropia privada que poderia ser usado para outros fins. Deste modo, as fontes da própria sobrevivência dos ecologistas políticos parecem estar sujeitas a obrigações especiais. Finalmente, a ecologia política marcou tão claramente sua própria postura normativa em defesa dos desfavorecidos do mundo que uma escolha, implícita ou explícita, para deixar de lado estas questões sobre as obrigações éticas, parece, na melhor das hipóteses, inconsistente.

Nas ciências sociais, tornou-se amplamente aceito (graças em parte aos ecologistas políticos) que pesquisar é um ato político. No entanto, ao falhar em examinar mais rigorosamente a ética de suas próprias práticas, a ecologia política abre-se para a mesma acusação que ela lançou sobre outros campos de estudo: de muito frequentemente ignorar a dimensão política e, por conseguinte, ética de suas próprias ações ou inações. Outra vez, deveria ser fortemente enfatizado que se "as ações de responsabilidade social" são a medida adequada da prática ética, há muitos ecologistas políticos cujas práticas satisfazem esta definição em qualquer medida. Contudo, há também uma proporção significativa da pesquisa em ecologia política que fornece uma crítica profundamente perspicaz, mas com poucas ligações óbvias com um progresso material ou social tangível para aqueles que são os sujeitos do estudo. O perigo sempre presente de que os conceitos na ecologia política possam ser cooptados para reforçar as velhas práticas exploratórias (BEBBINGTON et al., 2003; RIBOT, 1996) levanta a questão perturbadora de que se pode presumir que a crítica e a teoria sem compromisso sejam socialmente ou ambientalmente benignas; ou se tal pesquisa pode ser também potencialmente maligna. Ainda mais fundamental, talvez, o ponto crucial de uma grande parte do debate até agora é se a própria crítica intelectual significa um comprometimento - uma questão que é em grande medida um assunto de filosofia pessoal. Assim, se os ecologistas políticos "dão" mais do que "tiram" vai sempre ser, até certo ponto, uma questão pessoal. Se os lugares fossem trocados e os africanos, latino-americanos e sul-asiáticos pobres, ou as minorias norte-americanas desfavorecidas, pesquisassem as práticas tribais e as lutas materiais e simbólicas pelos recursos entre a elite privilegiada dos ecologistas políticos norte-americanos e europeus, suas conclusões sobre esta questão poderiam ser esclarecedoras.

\section{Agradecimentos}

Não teria sido possível escrever este artigo sem os comentários perspicazes de Tom Bassett, Simon Batterbury, Tony Bebbington, Piers Blaikie, Julia Haggerty, James McCarthy, Bret McCusker, Rod Neumann, Karl Offen, Eric Perramond, Paul Robbins, Farhana Sultana e Karl Zimmerer. Erros, omissões e ofensas são unicamente culpa do autor.

\footnotetext{
15 "liberation ecology".
} 


\section{Referências}

BATTERBURY, S.; HOROWITZ, L. Engaged political ecology. Durham, NC: Duke University Press, 2007, in press.

BEBBINGTON, A. Livelihoods and resource accessing in the Andes: desencuentros in theory and practice. In: GOUGH, I.; McGREGOR, J. A. (Eds.). Well-being in development countries: new approaches and research strategies. Cambridge: Cambridge University Press, 2007, in press.

; LEWIS, D.; BATTERBURY, S.; OLSON, E. Of texts and practices: organizational cultures and the practice of empowerment in World Bank funded programs. Paper read at Order and Disjuncture: The Organization of Aid and Development, 26-27 September, at SOAS London, 2003.

; SIDIQI, S. Of texts and practices: organizational cultures and the practice of empowerment in World Bank-funded programs. Journal of Development Studies, 2007, in press.

BLAIKIE, P.; BROOKFIELD, H. (Eds.). Land degradation and society. London and New York: Methuen, 1987.

BRYANT, R. L.; JAROSZ, L. Ethics in political ecology: a special issue of Political Geography. Introduction: thinking about ethics in political ecology. Political Geography, v. 23, p. 807-812, 2004.

CLOKE, P. Deliver us from evil? Prospects for living ethically and acting politically in human geography. Progress in Human Geography, v. 26, p. 587-604, 2002.

CORBRIDGE, S. Marxisms, modernities, and moralities - development praxis and the claims of distant strangers. Environment and Planning D: Society and Space, v. 11, p. 449-472, 1993.

DRIVER, F. Morality, politics, geography: brave new words. In: PHIILO, C. (Ed.). New words, new worlds: reconceptualising social and cultural geography. Lampeter: St. David's University College, 1991.

FORSYTH, T. Critical political ecology: the politics of environmental science. London: Routledge, 2003.

; WALKER, A. Crisis? The politics of environmental knowledge in northern Thailand. Seattle: University of Washington Press, 2007, in press.

GUHA, R. Radical American environmentalism and wilderness preservation: a Third World critique. Environmental Ethics, v. 11, p. 71-83, 1989.
JAROSZ, L. Political ecology as ethical practice. Political Geography, v. 23, p. 917-927, 2004.

LEACH, M.; MEARNS, R. The lie of the land: challenging received wisdom on the African environment. London: James Currey, 1996.

NAESS, A. The shallow and the deep, long-range ecology movements: a summary. Inquiry, v. 1, n. 16, p. 95-100, 1973.

PAULSON, S.; GEZON, L. L.; WATTS, M. Locating the political in political ecology: an introduction. Human Organization, v. 62, p. 205-217, 2003.

PEET, R.; WATTS, M. Liberation ecologies: environment, development, social movements. London: Routledge, 1996.

RIBOT, J. Participation without representation: chiefs, councils, and forestry law in the West African Sahel. Cultural Survival Quarterly, v. 30, p. 40-44, 1996.

ROBBINS, P. Political ecology: a critical introduction. Critical introductions to geography. Malden, MA: Blackwell, 2004.

ROCHELEAU, D. The invisible ecologies of Machakos; landscape, livelihoods, and life stories 1890-1990. New York: United Nations University Press, 2007, in press.

ROCHELEAU, D. E.; THOMAS-SLAYTER, B. P.; WANGARI, E. Feminist political ecology: global issues and local experience. International studies of women and place. London and New York: Routledge, 1996.

SAYER, A.; STORPER, M. Ethics unbound: For a normative turn in social theory. Environment and Planning D: Society and Space, v. 15, p. 1-17, 1997.

SAYRE, N. F. Working wilderness: the Malpai Borderlands Group and the future of the western range. Tucson, AZ: Rio Nuevo Publishers, 2005.

SINGER, P. Famine, affluence, and morality. Philosophy and Public Affairs, v. 1, p. 229-243, 1972.

SMITH, D. M. Moral geographies: ethics in a world of difference. Edinburgh: Edinburgh University Press, 2000.

STOTT, P. A.; SULLIVAN, S. Political ecology: science, myth and power. Oxford: Oxford University Press, 2000.

VAYDA, A. P.; WALTERS, B. B. Against political ecology. Human Ecology, v. 27, p. 167-179, 1999. 
WALKER, P. A. Political ecology: where is the policy? Progress in Human Geography, v. 30, p. 382-395, 2006.

WATTS, M. J. Review of Land degradation and society, by Piers Blaikie and Harold Brookfield, 1987. Capitalism, Nature, Socialism, v. 4, p. 123-131, 1990.
. Political ecology. In: SHEPPARD, E.; BARNES, T. (Eds.). A companion to economic geography, Malden, MA: Blackwell, p. 590-593, 2000.

Recebido em junho de 2011. Aceito em novembro de 2011.

Publicado em junho de 2012. 